\title{
Increased dissolution rates of tranilast solid dispersions extruded with inorganic excipients
}

\author{
M. Maniruzzaman ${ }^{1}$, M.T. Islam ${ }^{1}$, N. Scoutaris ${ }^{1}$, A. Nair ${ }^{2}$, Dennis Douroumis ${ }^{1}$ *
}

${ }^{1}$ Faculty of Engineering and Science, School of Science, University of Greenwich, Chatham Maritime, Chatham, Kent ME4 4TB, UK

${ }^{1}$ Fuji Chemical Industry Co., Ltd., 12F, The Front Tower Shiba Koen, 2-6-3 Shibakoen, Minato-Ward, Tokyo, 105-0011 Japan

*Correspondence: Faculty of Engineering and Science, University of Greenwich, Medway Campus, Chatham Maritime, Kent ME4 4TB, UK. Tel.: +44 (0) 208331 8440; Fax: +44 (0) 2083319805.

E-mail address: D.Douroumis@gre.ac.uk (D. Douroumis). 


\begin{abstract}
The purpose of this study was to evaluate the performance of Neusilin ${ }^{\circledR}$ (NEU) a synthetic magnesium aluminometasilicate as inorganic drug carrier co-processed with the hydrophilic surfactants Labrasol and Labrafil to develop Tranilast (TLT) based solid dispersions using continuous melt extrusion (HME) processing. Twin - screw extrusion was optimized to develop various TLT/excipient/surfactant formulations followed by continuous capsule filling in the absence of any downstream equipment. Physicochemical characterisation showed the existence of TLT in partially crystalline state in the porous network of inorganic NEU for all extruded formulations. Furthermore, the in line NIR studies revealed a possible intermolecular $\mathrm{H}$-bonding formation between the drug and carrier resulting in the increase of dissolution of TLT. The capsules containing TLT extruded solid dispersions showed enhanced dissolution rates and compared with the marketed Rizaben ${ }^{\circledR}$ product.
\end{abstract}

Keywords: extrusion, solid dispersions, excipients, drug - excipient interactions dissolution. 


\section{Introduction}

Today pharmaceutical industry undergoes a transition from conventional batch manufacturing production to continuous processing. Due to market globalization, pharmaceutical industries are facing immense challenges to comply with the demands of regulatory agencies while the reduced patent life and overall decreased profitability of newly discovered drug substances forces them to shorten the drug development times with maximum throughput. Therefore, continuous manufacturing processes $(\mathrm{CM})$ can be proved an efficient and promising alternative for achieving these goals ${ }^{1}$. $\mathrm{CM}$ provides better product quality assurance than batch process with less labour cost and time for development. Furthermore, strong efforts are taken on the implementation of process analytical tools (PAT) for the purposes of in-line process monitoring and quality control ${ }^{2-4}$.

To date, hot melt extrusion (HME) has been utilised to a great extent for the development and optimisation of solid dispersions ${ }^{5-13}$ in order to enhance the dissolution rate of water insoluble drugs ${ }^{15-16}$. Although HME is a versatile technology and can be used for continuous manufacturing of various pharmaceutical dosage forms, it has not yet fully exploited for such purposes. Continuous HME offers several advantages such as small footprint, cost efficiency, reduced material waste and coupling with various process analytical tools (PAT).

The processing of inorganic excipients ${ }^{17,18}$ as drug carries to increase dissolution rates of water insoluble drugs has recently gain interest for the development of solid dispersions. Bahl et al., evaluated the solubility and dissolution profiles of the poorly water soluble drug indomethacin co-processed with Neusilin, an inorganic carrier ${ }^{19}$ using ball milling micronization. The author found that the presence of silicic acid and $\mathrm{Mg}^{2+} / \mathrm{Al}^{3+}$ ions, of $\mathrm{NEU}$ in the dissolution media increased the concentration of indomethacin and enhanced its in vitro dissolution rates. Maclean et al. (2011), described a robust extrusion process involving hot melt extrusion to form a Sulindac-NEU amorphous drug complex to enhance the dissolution rate of sulindac ${ }^{20}$.

Recently, Maniruzzaman et el., conducted extrusion studies to assess the performance of synthetic magnesium aluminometasilicate as an inorganic carrier for the development of stable indomethacin (IND) solid dispersions. Several IND/NEU blend ratios $(20 \%, 30 \%$ and $40 \%$ ) were extruded continuously using a twin - screw extruder resulting in enhanced drug dissolution rates while the solid dispersions were stable over12 months ${ }^{21}$. The same group reported another study of an extrusion granulation process for the increased dissolution of the water insoluble ibuprofen (IBU). A quality-by-design (QbD) approach was implemented 
through a design of experiment to produce IBU loaded granules. The extruded granules showed significant enhancement in the dissolution profiles of ibuprofen attributed to the intermolecular interactions of the drug and the inorganic carrier ${ }^{22}$.

Neusilin ${ }^{\circledR}(\mathrm{NEU})$ is considered a synthetic magnesium aluminometasilicate ${ }^{23}$ that exhibits exceptional physical properties for improved drug delivery (e.g. high specific surface area, high flowability, amorphous). Tranilast is classified as a BCS class II drug with solubility in water and acidic medium $(\mathrm{pH} 1.2)$ of 14.5 and $0.7 \mu \mathrm{g} / \mathrm{mL}$, respectively ${ }^{24,25}$.

Up to date most of the research focuses on the HME processing of polymers, lipids or inorganic excipients as single drug carriers. Herein we present a two-fold study where inorganic excipients are co-processed with a variety of surfactant/solubilizers to produce stable solid lipid dispersions with enhanced drug dissolution rates. In addition HME processing was optimized for continuous manufacturing of TLT capsules by direct feeding of the extruded formulations in a capsule-filling machine.

\section{Materials and method}

\subsection{Materials}

Tranilast (TLT) ( $\geq 98 \%$ ) was purchased from Tokio Chemical Industries (Japan) and Neusilin (NEU) ( $\geq$ 99\%) was kindly donated by Fuji Chemical Industries Co., Ltd. (Japan). Labrasol (LSOL) ( $\geq 98 \%$ ) and Labrafil (LFIL) ( $\geq 98 \%$ ) were kindly donated by Gattefosse, France. All solvents used were of analytical grade and used as received.

\subsection{Solubility study of TLT is surfactants}

Phase solubility study was performed to know the solubility of TLT in the presence of various surfactants in buffer solution ( $\mathrm{pH}$ 6.8). An excess quantity of TLT was placed in 20 $\mathrm{ml}$ tube containing $10 \mathrm{ml}$ of buffer medium with 1-5\% surfactants (w/w). All test tubes were subjected to sonication for $20 \mathrm{~min}$ at room temperature followed exposure to orbital shaking thermo stable incubator (Boekel Scientific, Germany) for $48 \mathrm{~h}$ at $37 \pm 0.5^{\circ} \mathrm{C}$ with rotating speed of 75 agitations /min. The supernatant solution was then passed through a Whatman filter Paper (Grade 1) and analyzed by HPLC to quantify the amount of TLT dissolved. The best two surfactants were chosen to undertake further experiments. 


\subsection{Continuous hot-melt extrusion processing and manufacturing of capsules}

All prepared binary or ternary mixtures with either LSOL or LFIL as surfactant were extruded at temperatures varying form $170-200^{\circ} \mathrm{C}$ to find the suitable extrusion temperatures (Table 1). The temperatures, screw speed and the torque forces were recorded for each processed sample. The screw speed used for extrusion was 50-100 rpm with a feed rate of 1 $\mathrm{kg} / \mathrm{hr}$. The EuroLab 16 is contacted to a terminal PC and all processing parameters can be controlled through the appropriate software supplied by Thermo Fisher. The extrudates were collected in powder forms so no additional down streaming processing were required and upon the optimization $180^{\circ} \mathrm{C}$ was used as the final extrusion temperature.

All extruded granules were fed to a Mini Cap capsule filler (Karnavati Engineering ltd, India) in line with the extruder in continuous manufacturing platform (Fig. 1). The machine output was set at 1500 capsules ( 0 size) per hour in an automatic mode.

\subsection{Scanning electron microscopy (SEM)}

The spatial distribution of discreet chemical phases was evaluated using a cold-cathode field-emission gun scanning electron microscope (Hitachi SU8030 FEG-SEM, Japan). The samples were placed on double-sided carbon adhesive tabs and coated with carbon (Edwards 306 high vacuum carbon evaporation) before SEM analysis. The surface analysis to characterize the morphology of the pellets was evaluated using SEM at a nominal magnification of $1000 \times($ area $=0.127 \mathrm{~mm} \times 0.095 \mathrm{~mm})$. The accelerating voltage of the incident electron beam was set at $8 \mathrm{kV}$. This value was selected in order to minimize beam damage to the sample while maintaining adequate excitation.

\subsection{Particle size analysis}

The particle size distributions of the granules were determined using a Mastersizer 2000 laser diffraction instrument (Malvern Instruments, UK) with a dry powder sample dispersion accessory (Scirocco 2000) and pressure at 0.5 bar and a vibration feed rate of 50\%. Samples were run in triplicates. Mastersizer 2000 software was used for data evaluation.

\subsection{Thermal analysis}

A Mettler-Toledo 823e (Greifensee, Switzerland) differential scanning calorimeter (DSC) was used to carry out DSC runs of pure actives, physical mixtures and extrudates. 2-5 $\mathrm{mg}$ of sample was placed in sealed aluminium pans with pierced lids. The samples were 
heated at $10^{\circ} \mathrm{C} / \mathrm{min}$ from $0^{\circ} \mathrm{C}$ to $220^{\circ} \mathrm{C}$ under dry nitrogen atmosphere and reheated at the same heating rate.

Thermogravimetric analysis (TGA) measurements were conducted synchronously on a Q5000 (Thermal Analysis Company, USA). The vesicle samples were frozen in a liquid nitrogen bath followed by a vacuum freeze-drying step before TGA and DSC measurements. The lyophilized samples were placed into the alumina crucible with nitrogen as the reference. The heating-rate was $10^{\circ} \mathrm{C} / \mathrm{min}$ from 25 to $250^{\circ} \mathrm{C}$.

\subsection{X-ray powder diffraction $(X R P D)$}

XRPD was used to determine the solid state of pure active substances, physical mixtures and extruded materials using a Bruker D8 Advance (Germany) in theta-theta mode. For the study purposes a $\mathrm{Cu}$ anode at $40 \mathrm{kV}$ and $40 \mathrm{Ma}$, parallel beam Goebel mirror, $0.2 \mathrm{~mm}$ exit slit, LynxEye Position Sensitive Detector with $3^{\circ}$ opening (LynxIris at $6.5 \mathrm{~mm}$ ) and sample rotation at $15 \mathrm{rpm}$ were used. Each sample was scanned from 2 to $40^{\circ} 2 \theta$ with a step size of $0.02^{\circ} 2 \Theta$ and a counting time of 0.1 seconds per step; 176 channels active on the PSD making a total counting time of 35.2 seconds per step.

\subsection{In-line Near Infra-Red (NIR) monitoring}

Near infrared spectrometry was performed during extrusion using an Antaris II NIR spectrometer (Thermo Scientific, UK) equipped with a halogen NIR source and InGaAs detector. The instrument utilised a fibre optic probe which was connected to the NIR spectrometer and used for in-line monitoring. NIR spectra were collected in real-time during the entire extrusion process via a fibre optic diffuse reflectance probe. All NIR in-line spectra were continuously collected using the RESULT Integration software (Version 3.0 Thermo Scientific, UK). Each spectrum was acquired by averaging 32 scans with a resolution of $16 \mathrm{~cm}^{-1}$ over the 4,000-10,000 $\mathrm{cm}^{-1}$ wavenumber range. The acquisition of a full spectrum took approximately $16 \mathrm{~s}$. The spectral pre-processing was performed using the TQ Analyst software (Version 8.6.12 Thermo Scientific, UK).

\subsection{In vitro dissolution study}

In vitro dissolution studies ${ }^{26}$ were conducted in $900 \mathrm{ml}$ of $0.2 \mathrm{M}$ dihydrogen-sodiumorthophosphate ( $\mathrm{pH}$ adjusted with $\mathrm{NaOH}$ to 6.8 ) for $2 \mathrm{~h}$ using a Varian 705 DS dissolution paddle apparatus (Varian Inc. North Carolina, US) at $100 \mathrm{rpm}$. All formulations were directly dropped in the vessels without filling them in a capsule $(n=3)$. Dissolution bath and vessels 
were equilibrated to $37 \pm 0.5^{\circ} \mathrm{C}$. At predetermined time intervals, samples were withdrawn for HPLC assay.

\subsection{HPLC analysis}

The release of TLT was determined by using HPLC, Agilent Technologies system 1200 series. A HYCHROME S50DS2-4889 (5 $\mu \mathrm{m}$ x $150 \mathrm{~mm}$ x 4mm) column was used for the HPLC analysis. The wavelength was set at $340 \mathrm{~nm}$. The mobile phase consisted of methanol/water/triethyl amine $(75 / 25 / 0.2 \mathrm{v} / \mathrm{v})$ and the flow rate was maintained at $1.0 \mathrm{ml} / \mathrm{min}$ and the retention time was 2-3 min. Calibration curve was prepared with concentrations varying from $10 \mu \mathrm{g} / \mathrm{ml}$ to $50 \mu \mathrm{g} / \mathrm{ml}$ and $20 \mu \mathrm{l}$ injection volumes.

\section{Results and discussion}

\subsection{HME processing and capsule manufacturing}

In order to optimize the extrusion processing parameters, various TLT based formulations of different ratios and compositions were processed under different extrusion temperatures varying from $170-200^{\circ} \mathrm{C}$. The solid-state analysis (see below), revealed that temperatures above $180^{\circ} \mathrm{C}$ are the most appropriate for the processing of TLT batches and the drug remained stable within the temperature range (melting point of TLT is above $200^{\circ} \mathrm{C}$ ). By using inorganic silicates as drug carrier the HME process optimization resulted in the production of free flowing granules. NEU is considered an excellent excipient for extrusion

purposes due to the high flowability (Carr's index 13), high specific surface area and the drug absorbance within the silicate porous network ${ }^{23}$.

The TLT solubility studies conducted using a range of hydrophilic surfactants (data not shown) revealed that both Labrafil and Labrasol have the highest solubilisation capacity for TLT in buffer solution ( $\mathrm{pH}$ 6.8). Therefore, these two surfactants were used as hydrophilic surfactants and co-processed with NEU at high drug loadings (40-60\% w/w ratios) as shown in Table 1. The extrusion of NEU in presence of liquid surfactants $(10-15 \% \mathrm{w} / \mathrm{w}$ ratios $)$ facilitated a complete dry blending resulting in the production of TLT loaded free flowing powders.

The excellent flowability of the extruded powders was also achieved even at $60 \%$ drug loadings despite the poor flow properties of IND and the surfactants used in the formulations. The estimated Carr's index values of TLT/NEU and TLT/NEU/surfactants extruded powders varied from 10-11, which are in the same range of the bulk inorganic NEU. The use of 
inorganic NEU and the process optimization in the absence of the extrusion die eliminated the downstream processing and provided high throughput of extruded formulations. Furthermore, HME was coupled successfully with an auto capsule filler MiniCap to manufacture capsules without the addition of other excipients. The process was allowed to operate continuously for $3 \mathrm{hr}$ and produced 1500 capsules (' 0 ' size) per hour.

\subsection{SEM and particle size analysis}

SEM analysis was used to investigate the surface morphology of the bulk substances and the extruded formulations. As shown in Fig. 2a for all of the TLT/NEU formulations with or without surfactants no drug crystals can be identifued on the NEU surface indicating excellent extrusion processing. Further observation shows that TLT/NEU extrudates formed agglomerates comprising of microstructured particles. The formation of agglomerates where the drug substance is adsorbed while the obtained particle size is similar to that of bulk NEU can be of great interest for the development of oral dosage forms (e.g. capsules) in a continuous manufacturing process without the requirement of further down-streaming processing. As shown in Fig. $2 b$ the determined particle size distribution of all extrudates and bulk NEU varied from $40-300 \mu \mathrm{m}(\mathrm{d}(0.9)=300 \mu \mathrm{m})$. Due to the drug/surfactant adsorption in the porous inorganic network no further micronization was required. .

\subsection{Thermal analysis}

The bulk materials, physical mixtures and extruded formulations were further investigated by DSC analysis. As shown in Fig. 3a, pure TLT presented a sharp endotherm corresponding to its melting peak at $213^{\circ} \mathrm{C}(\Delta \mathrm{H}=155.27 \mathrm{j} / \mathrm{g})$. Synthetic NEU didn't present any reversible thermal transition below $250^{\circ} \mathrm{C}$ in MTDSC (only a non-reversible thermal transition was seen at $165^{\circ} \mathrm{C}$ ), which could be due to the water loss of the two water molecules in NEU structure (Supp. Fig. 1).

TLT/NEU (60/40 w/w) physical mixture (F3) showed a sharp endothermic thermal transition due to the melting of the drug at $213^{\circ} \mathrm{C}(\Delta \mathrm{H}=174.51 \mathrm{~J} / \mathrm{g})$ (Fig. 3a). In contrast in the extruded formulation a slight sift of the TLT melting endotherm at $211.89^{\circ} \mathrm{C}(\Delta \mathrm{H}=160.01$ $\mathrm{J} / \mathrm{g}$ ) was observed. As shown in similar studies ${ }^{27}$ of porous carriers the endothermic shift simply indicates the co-existence of amorphous and crystalline TLT in the porous network. A similar phenomenon was observed in TLT/NEU/LSOL extruded formulation (F5) with a significant shift of the melting endotherm towards lower temperatures at $202.37^{\circ} \mathrm{C}$. In the 
physical blends of F5, TLT showed a melting peak at $212.19^{\circ} \mathrm{C}$, which was shifted at $201.33^{\circ} \mathrm{C}$ after the extrusion processing. In both cases the shift in the melting peak of TLT can be attributed to the presence of surfactant in the system. The liquid LSOL has partially solubilized TLP facilitating further adsorption in the inorganic carrier. It can also be seen that the melting peaks differ in shape where broader peaks suggest more drug melted within the pores. This indicates that the presence of hydrophilic surfactant such as LSOL may have played a key role to TLT solubilization during the extrusion process, which in turn is expected to show an impact in the in vitro dissolution rates.

Thermo-gravimetric (TGA) analysis was performed to determine any potential material weight loss as a function of the increasing temperatures. As can be seen in Fig. 3b bulk TLT has not showed any weight loss up to $205^{\circ} \mathrm{C}$ while bulk NEU showed a net weight loss of about $12.0 \%$ at $200^{\circ} \mathrm{C}$ corresponding to the loss of two molecules. A similar thermal transition was observed in the MTDSC analysis as mentioned above. The bulk LSOL showed weight loss of $5.24 \%$ which is expected to not to provide any significant impact in the extruded formulations considering only $10 \% \mathrm{w} / \mathrm{w}$ ratio in the final formulation prior to the extrusion processing. Both the TLT/NEU and TLT/NEU/LSOL extruded formulations exhibited lower weight losses of $5.40 \%$ and $3.70 \%$ respectively. These weight losses are quite lower compared to bulk NUE suggesting that $\mathrm{H}_{2} \mathrm{O}$ molecules were not completely removed when NEU was co-processed with TLT or TLT/LSO.

\subsection{X-ray powder diffraction (XRPD) studies}

$\mathrm{X}$-ray powder diffraction analysis of bulk substances and extruded granules, was performed in order to examine the physical state of the drug substance. As can be seen in Fig. 4 and Supp. Fig. 2 the diffractogram of bulk TLT showed distinct intensity peaks due to its crystalline structure at $11.06^{\circ}, 12.17^{\circ}, 13.78^{\circ}, 16.67^{\circ}, 18.64^{\circ}, 22.41^{\circ}, 24.63^{\circ}, 28.46^{\circ}, 31.07^{\circ}$ $2 \theta$ degrees while NEU appeared as completely amorphous with no crystalline intensity peaks. The physical blends of all TLT formulations showed identical peaks without any reduction of the peak intensities due to the presence of crystalline TLT. Similarly, all extruded granules showed identical peaks at relatively lower intensities suggesting lower degree of crystalline TLT and increase of the amorphous content during the extrusion processing even at high $60 \%$ drug loading. 


\subsection{In- line NIR spectroscopy monitoring}

Off-line NIR spectra of bulk TLT, excipients and physical blends were recorded in order to identify the characteristic bands of the bulk substances. An in-line NIR reflectance probe was coupled on the HME process to continuously monitor ${ }^{28,29}$ all of the TLT based formulations. Furrhet, in-line NIR spectra of the TLT/NEU 60/40 (w/w) formulation were recorded during the extrusion at the third mixing zone. The second derivative spectra in Fig. 5a-d shows a significant peak shift between the NIR spectra of bulk TLT and that in the extruded granules. The NIR signal of NEU was flat in the same region suggesting no effect on the drug absorption. In Fig. 5a it can be seen that the second derivative NIR spectra showed a significant peak shift, particularly in the range of $8800-8900 \mathrm{~cm}^{-1}$, indicating potential intermolecular interactions between the drug and the complex silicate. Interestingly, the dimer peaks of the bulk TLT at $8800-8900 \mathrm{~cm}^{-1}$ disappeared in the extruded granules and showed a broad peak, which could be due to the interactions and also could be attributed to the increase the amorphicity of the extruded materials.

Furthermore, Fig. 5b shows that a peak at $7095 \mathrm{~cm}^{-1}$ attributed to the $-\mathrm{OH}$ stretching first overtone of the drug TLT has been shifted to a new position at $7109 \mathrm{~cm}^{-1}$ in the TLT/NEU extrudates. The peak shifting at this position is probably due to the H-bonding between the $\mathrm{COOH}$ of TLT and the $-\mathrm{O}$ group of NEU ${ }^{30}$. There are also two more peaks at $7385 \mathrm{~cm}^{-1}$ and $7212 \mathrm{~cm}^{-1}$ were shifted from $7402 \mathrm{~cm}^{-1}$ and $7234 \mathrm{~cm}^{-1}$ respectively. These two peaks are attributed to the $-\mathrm{CH}$ stretching, and the reason of the peak shifting occurs is could be due to the formation of weak H-bond $(\mathrm{C}-\mathrm{H} \cdots \mathrm{O})$ between the drug and the excipient ${ }^{31}$. Furthermore, another peak at $5206 \mathrm{~cm}^{-1}$ which is attributed to the $\mathrm{C}=\mathrm{O}$ second overtone has also been shifted to $5230 \mathrm{~cm}^{-1}$ (Fig. 5c). This peak shifting is due to the formation of H-bond between the $-\mathrm{C}=\mathrm{O}$ of the drug and the excipient. The amide group (-CONH-R) of the drug was visible via an intense peak at $4668 \mathrm{~cm}^{-1}$, which has been slightly shifted and appears broader after the extrusion processing (Fig. 5d). This could be attributed to the increase in the amorphicity of the drug in the extruded formulations as confirmed by the XRD and DSC studies.

\subsection{In vitro dissolution studies}

In vitro dissolution studies of TLT formulations were compared with the bulk TLT and the commercial formulation (Rizaben $\left.{ }^{\circledR}\right)$. The studies showed a significant improvement in the drug release at phosphate buffer $(\mathrm{pH}$ 6.8). As shown in Fig. 6a for the first 60 min the TLT/NEU extruded (60\% TLT loading $\mathrm{w} / \mathrm{w})$ formulation and Rizaben ${ }^{\circledR}$ presented similar 
profiles $(\mathrm{p}>0.05)$ with release profiles varying from $70-80 \%$. However, after $120 \mathrm{~min}$ the extruded formulation presented $100 \%$ TLT dissolution rates while Rizaben ${ }^{\circledR}$ reached a maximum of $81-84 \%$. The increase of TLT loading in the extruded formulations did not affect the dissolution rates, which were similar as shown in Fig. 6a. It can also be seen that the dissolution rate of bulk TLT was approximately $40 \%$ after $120 \mathrm{~min}$.

As shown in Fig. $6 \mathrm{~b}$ for the, co-processed NEU/LSOL extrudates the TLT dissolution rates were again similar to Rizaben ${ }^{\circledR}$ at $76 \%$ after $30 \mathrm{~min}$ but significantly higher after $60 \mathrm{~min}$. The TLT/NEU/LFIL extrudate showed slower dissolution rates with around $61 \%$ for the first $60 \mathrm{~min}$ compared to TLT/NEULSOL and Rizaben ${ }^{\circledR}$ respectively and $95 \%$ at $120 \mathrm{~min}$.

The observed increase in the dissolution studies of TLT extruded formulations could be attributed to the effect of sinalol groups in NEU. As previously reported, NEU generates various silanol groups (e.g. free, germinal or associated) when in contact with water render it it a potential proton donor as well as a proton acceptor ${ }^{22}$. The existence of free silicic acid and ions $\left(\mathrm{Mg}^{2+}\right.$ and $\left.\mathrm{Al}^{3+}\right)$ in the dissolution media may have played a vital role to cause the increase in the dissolution of TLT. Similar results were observed from Bahl et al. for indomethacin solid dispersions. In the present study, the increase dissolution rates in the presence of LSOL or LFIL within the extruded formulations is due to the solubilising capacity of the two surfactants. However, as shown in Fig. $6 \mathrm{~b}$ the presence of LSOL in the extrudates resulted in better dissolution rates compared to LFIL due to its better solubilizing effect on TLT as confirmed by the saturation solubility data (Supp. Fig. 3).

\section{Conclusions}

In the current study inorganic aluminocilicates were processed with or without surfactants and exploited as a suitable drug carrier for continuous extrusion processing to produce capsules with enhanced dissolution rates of the poorly water-soluble drug TLT. The process comprised of only 3 operational units for continuous extrusion processing followed by capsule filling in the absence of any downstream equipment. The process optimization resulted in $60 \%$ TLT loadings with excellent powder flowability of the extruded formulations. Physicochemical characterization showed drug adsorption in the porous inorganic network while the present of surfactants increase TLP solubilization within the NEU carrier. In vitro dissolution studies revealed a significant increase of the dissolution 
rates of TLT compared to that of commercial capsules Rizaben. Inorganic excipients were used as a paradigm for drug extrusion though continuous capsule filling.

\section{Conflict of interest}

The authors declare no conflict of interests.

\section{Acknowledgments}

This work was financially supported by the Fuji Chemical Industry Co., Ltd., Japan.

\section{REFERENCES}

1. Melocchi, A., Loreti, G., Del Curto, M.D., Maroni, A., Gazzaniga A., Zema, L. 2015. Evaluation of Hot-Melt Extrusion and Injection Molding for Continuous Manufacturing of Immediate-Release Tablets J Pharm Sci. 104(6), 1971-1980.

2. Tiwari RV, Patil H, Repka MA. 2016. Contribution of hot-melt extrusion technology to advance drug delivery in the 21 st century. Expert Opin Drug Deliv. 13(3), 451-64

3. Maniruzzaman M, Douroumis D. 2015. Continuous manufacturing and process analytical tools. Int. J Pharm. 496 (1) 1-2.

4. Abu-Diak OA, Jones DS, Andrews GP. 2012. Understanding the performance of meltextruded poly(ethylene oxide)-bicalutamide solid dispersions: Characterisation of microstructural properties using thermal, spectroscopic and drug release methods. $\mathrm{J}$ Pharm Sci., 101 (1), 200-213

5. Park JB, Prodduturi S, Morott J, Kulkarni VI, Jacob MR, Khan SI, Stodghill SP, Repka MA, 2015. Development of an antifungal denture adhesive film for oral candidiasis utilizing hot melt extrusion technology, Expert Opin. Drug Deliv. 12 (1), 1-13

6. Andrews GP, Jones DS. 2014. Hot melt extrusion-processing solid solutions?, J. Pharm. Pharmacol., 66 (2), 145-147.

7. Pina MF, Zhao M, João, Pinto JF, Sousa JJ, Craig DQM. 2014. The Influence of Drug Physical State on the Dissolution Enhancement of Solid Dispersions Prepared Via HotMelt Extrusion: A Case Study Using Olanzapine. J Pharm Sci. 103(4), 214-1223

8. Jones DS, Margetson DN, McAllister MS, Yu, T, Shu L, McCoy CP, Andrews GP. 2014. Thermodynamically stable amorphous drug dispersions in amorphous hydrophilic polymers engineered by hot melt extrusion, Chem. Eng. Res. 92(12), 3046 $-54$ 
9. Liu H, Zhang X, Suwardie H, Wang P, Gogos C.G. 2012. Miscibility studies of indomethacin and Eudragit ${ }^{\circledR}$ E PO by thermal, rheological, and spectroscopic analysis. J Pharm Sci., 2012, 101(6), 2204-2212

10.Qi S, Belton P, Nollenberger K, Clayden N, Reading M, Craig DQM. 2010. Characterization and prediction of phase separation in hot-melt extruded solid dispersions: a thermal, microscopic and NMR relaxometry study. Pharm. Res. 27, 1869-1883.

11. Crowley MM, Zhang F, Repka MA, Thumma S, Upadhye SB, Battu SK, McGinity JW, Martin C. 2007. Pharmaceutical applications of hot-melt extrusion: part I, Drug Dev. Ind. Pharm., 33(9), 909-926.

12. Tackenberg MW, Krauss R, Marmann A, Thommes M, Schuchmann HP, Kleinebudde P. 2015. Encapsulation of liquids using a counter rotating twin screw extruder. Eur J Pharm Biopharm. 89:9-17

13. Kalivoda A, Fischbach M, Kleinebudde P. 2012. Application of mixtures of polymeric carriers for dissolution enhancement of fenofibrate using hot-melt extrusion. Int $\mathrm{J}$ Pharm. 429(1-2) 58-68

14. Maniruzzaman M, Rana, MM, Boateng JS, Mitchell JC, Douroumis D. 2013. Drug Dev Ind Pharm. 39, 218-27.

15. Gryczke A, Schminke GS, Maniruzzaman M, Beck J, Douroumis D. 2011. Development and evaluation of orally disintegrating tablets (ODTs) containing ibuprofen granules prepared by hot melt extrusion. Colloids Surf B Biointerfaces 86, 275-84.

16. Lang B, McGinity JW, Williams III RO. 2014. Hot-melt extrusion - basic principles and pharmaceutical applications. Drug Dev Ind Pharm 40(9), 1133-55.

17. Gupta MK, Tseng Y-C, Goldman D, Bogner RH. 2002. Hydrogen Bonding with Adsorbent during Storage Governs Drug Dissolution from Solid-Dispersion Granules. Pharm Res 19, 1663-72.

18. Kinoshita M, Baba K, Nagayasu A, Yamabe K, Shimooka T, Takeichi YI, Azuma M, Houchi, H, Minakuchi K. 2002. Improvement of solubility and oral bioavailability of a poorly water-soluble drug, TAS-301, by its melt-adsorption on a porous calcium silicate. J. Pharm. Sci. 912, 362-370.

19.Bahl D, Bogner RH. 2008. Amorphization Alone Does Not Account for the Enhancement of Solubility of Drug Co-ground with Silicate: The Case of Indomethacin. AAPS PharmSciTech 9, 146-153. 
20. Maclean J, Medina C, Daurio D, Alvarez-Nunez F, Jona J, Munson E, Nagapudi K. 2011. Manufacture and performance evaluation of a stable amorphous complex of an acidic drug molecule and neusilin. J Pharm Sci 100, 3332-44.

21. Maniruzzaman M, Nair A, Renault M, Nandi U, Scoutaris N, Farnish R, Bradley MS, Snowden MJ, Douroumis D. 2015. Continuous twin-screw granulation for enhancing the dissolution of poorly water-soluble drugs. Int. J Pharm. 496(1), 52-62.

22. Maniruzzaman M, Nair A, Scoutaris N, Bradley MS, Snowden M.J, Douroumis D. 2015. One-step continuous extrusion process for the manufacturing of solid dispersions, Int J Pharm. 496(1), 42-51.

23. Neuslin ${ }^{\circledR}$ technical brochure; Fuji chemical industry co., ltd., Japan (www.neusilin.com): last accessed 10 ${ }^{\text {th }}$ March 2014.

24. Kawabata Y, Yamamoto K, Debari K, Onoue S, Yamada S. 2010. Novel crystalline solid dispersion of tranilast with high photostability and improved oral bioavailability. Eur. J. Pharm. Sci., 39, 256-262.

25. The Society of Japanese Pharmacopoeia: Tranilast. Japanese Orange Book No. 12 Approved drug products with therapeutic equivalence evaluations $¥$, Tokyo, Yakuji Nippo Ltd., 2002, p 171.

26.US

pharmacopoeia,

2015 ,

http://www.pharmacopeia.cn/v29240/usp29nf24s0_m40420.html; last accessed Sep 2015.

27.Fatouros, DG, Douroumis D, Nikolakis V, Ntais S, Moschovi, AM, Trivedi, V, Khima, B, Roldo, M, Nazar, H, Cox PA. In vitro and in silico investigations of drug delivery via zeolite BEA. 2011. J. Mater. Chem. 21, 7789

28. Saerens L, Dierickx L, Quinten T, Adriaensens P, Carleer R, Vervaet C, Remon JP, De Beer, T. 2012. In-line NIR spectroscopy for the understanding of polymer- drug interaction during pharmaceutical hot-melt extrusion, Eur. J. Pharm. Biopharm. 81, $230-237$.

29. Coates PD, Barnes SE, Sibley MG, Brown EC, Edwards HGM, Scowen IJ. 2003. Inprocess vibrational spectroscopy and ultrasound measurements in polymer melt extrusion, Polymer 44, 5937-5949.

30.Islam MT, Scoutaris N, Maniruzzaman M., Moradiya HG, Halsey SA, Bradley MS, Chowdhry BZ, Snowden MJ, Douroumis D. 2015. Implementation of transmission NIR as a PAT tool for monitoring drug transformation during HME processing, Eur $\mathrm{J}$ Pharm Biopharm. 96, 106-16. 
31.Desiraju GR. 2005. C-H $\cdots \mathrm{O}$ and other weak hydrogen bonds. From crystal engineering to virtual screening. Chem. Comm. 24, 2995-3001.

Table 1: Formulation composition of TLT based formulations

\begin{tabular}{|c|c|c|c|c|}
\hline Formulation & $\begin{array}{c}\text { TLT } \\
(\mathbf{w} / \mathbf{w})\end{array}$ & $\begin{array}{l}\text { NEU } \\
(\mathbf{w} / \mathbf{w})\end{array}$ & $\begin{array}{l}\text { LSOL } \\
\text { (w/w) }\end{array}$ & $\begin{array}{l}\text { LFIL } \\
(w / w)\end{array}$ \\
\hline 1 & 40 & 60 & & \\
\hline 2 & 40 & 30 & & \\
\hline 3 & 60 & 40 & & \\
\hline 4 & 60 & 25 & 15 & \\
\hline 5 & 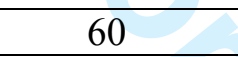 & 25 & & 15 \\
\hline 6 & 60 & 30 & 10 & \\
\hline 7 & 60 & 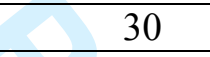 & & 10 \\
\hline \multicolumn{5}{|c|}{$\begin{array}{c}\text { 50/170/180/180/180/180/180/180/180 }{ }^{\circ} \mathrm{C}(\text { Feeder to die }) \\
\text { Screw speed: } 100 \mathrm{rpm} \text {, Feed rate: } 1 \mathrm{~kg} / \mathrm{h}\end{array}$} \\
\hline
\end{tabular}




\section{$\underline{\text { Figures caption list }}$}

Fig. 1 Schematic diagram of manufacturing TLT based capsule in a continuous process.

Fig. 2a SEM images of (a-b) TLT/NEU 60/40 and (c-d) TLT/NEU/LSOL 60/30/10 extruded formulations.

Fig. 2b Particle size distribution of TLT extruded formulations comparing to the bulk NEU.

Fig. 3a DSC thermal transitions of bulk TLT, TLT/NEU 60/40, TLT/NEU/LSOL 60/30/10 and TLT/NEU/LFIL 60/30/10 formulations.

Fig. 3b TGA thermograms of bulk TLT, NEU, TLT/NEU and TLT/NEU/LSOL extruded formulations.

Fig. 4 XRD difffractograms of bulk TLT, NEU and TLT based physical mixtures (PM) and extruded formulations (EXT).

Fig. 5 (a-d) $2^{\text {nd }}$ derivative NIR spectra of TLT, NEU and TLT/NEU formulations.

Fig. 6a In vitro TLT dissolution profiles of Rizaben and extruded formulation $(\mathrm{n}=$ $3, \mathrm{pH} 6.8)$.

Fig. 6b In vitro TLT dissolution profiles of Rizaben and co-processed extruded formulations with NEU/LSOL (LFIL) (n=3, pH 6.8). 


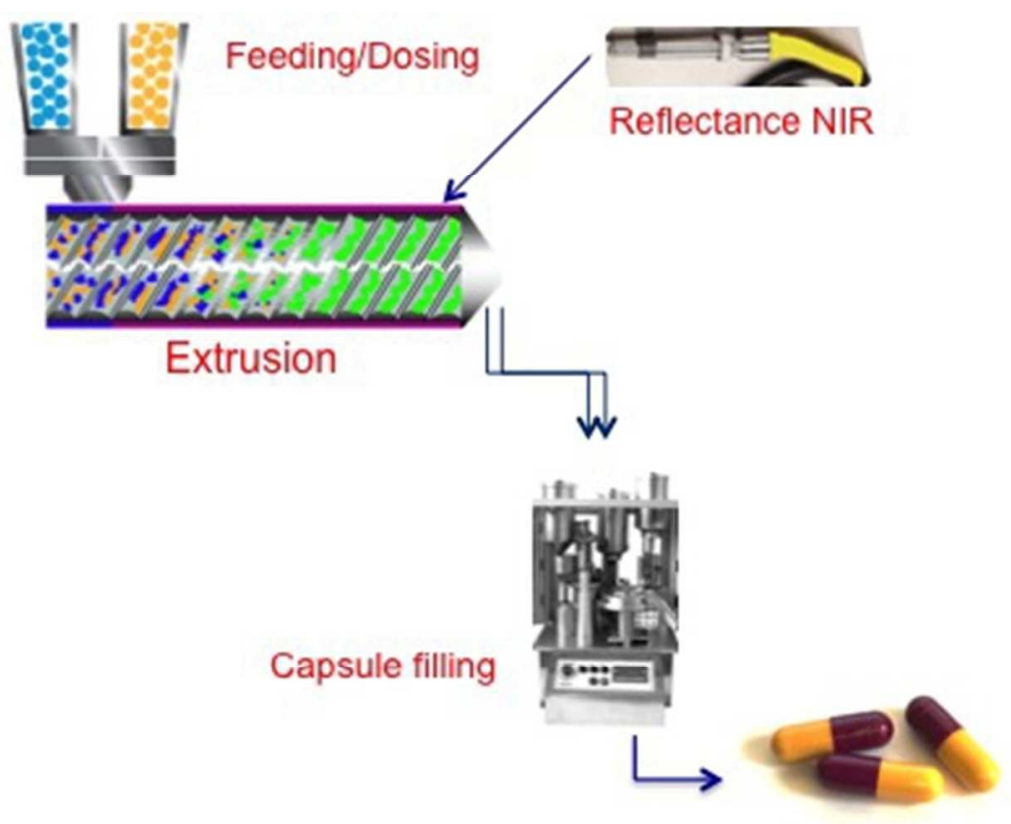

Schematic diagram of manufacturing TLT based capsule in a continuous process.

$138 \times 110 \mathrm{~mm}(72 \times 72 \mathrm{DPI})$ 

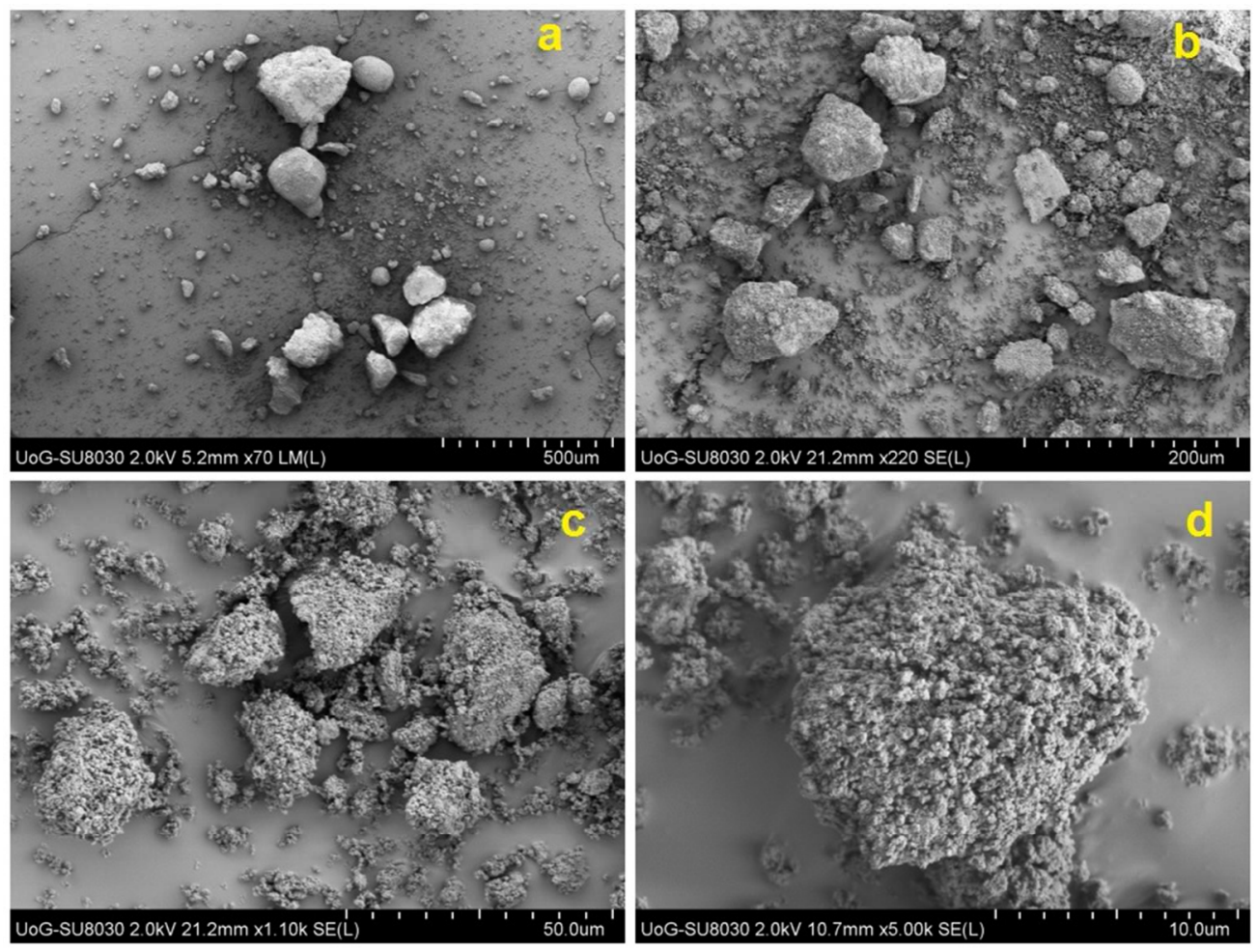

SEM images of (a-b) TLT/NEU 60/40 and (c-d) TLT/NEU/LSOL 60/30/10 extruded formulations.

$259 \times 195 \mathrm{~mm}(96 \times 96 \mathrm{DPI})$ 

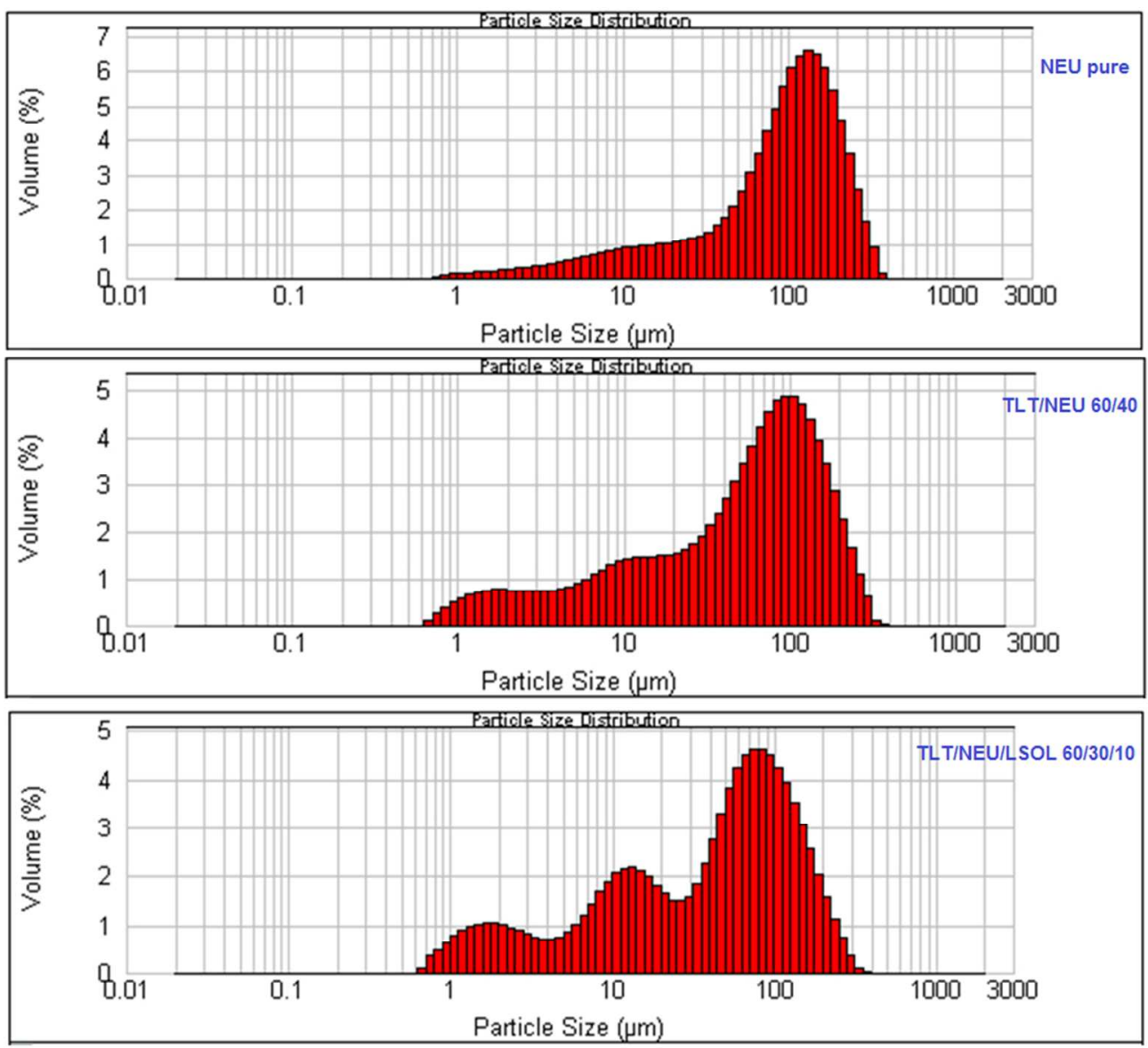

Particle size distribution of TLT extruded formulations comparing to the bulk NEU.

$236 \times 213 \mathrm{~mm}(96 \times 96 \mathrm{DPI})$ 

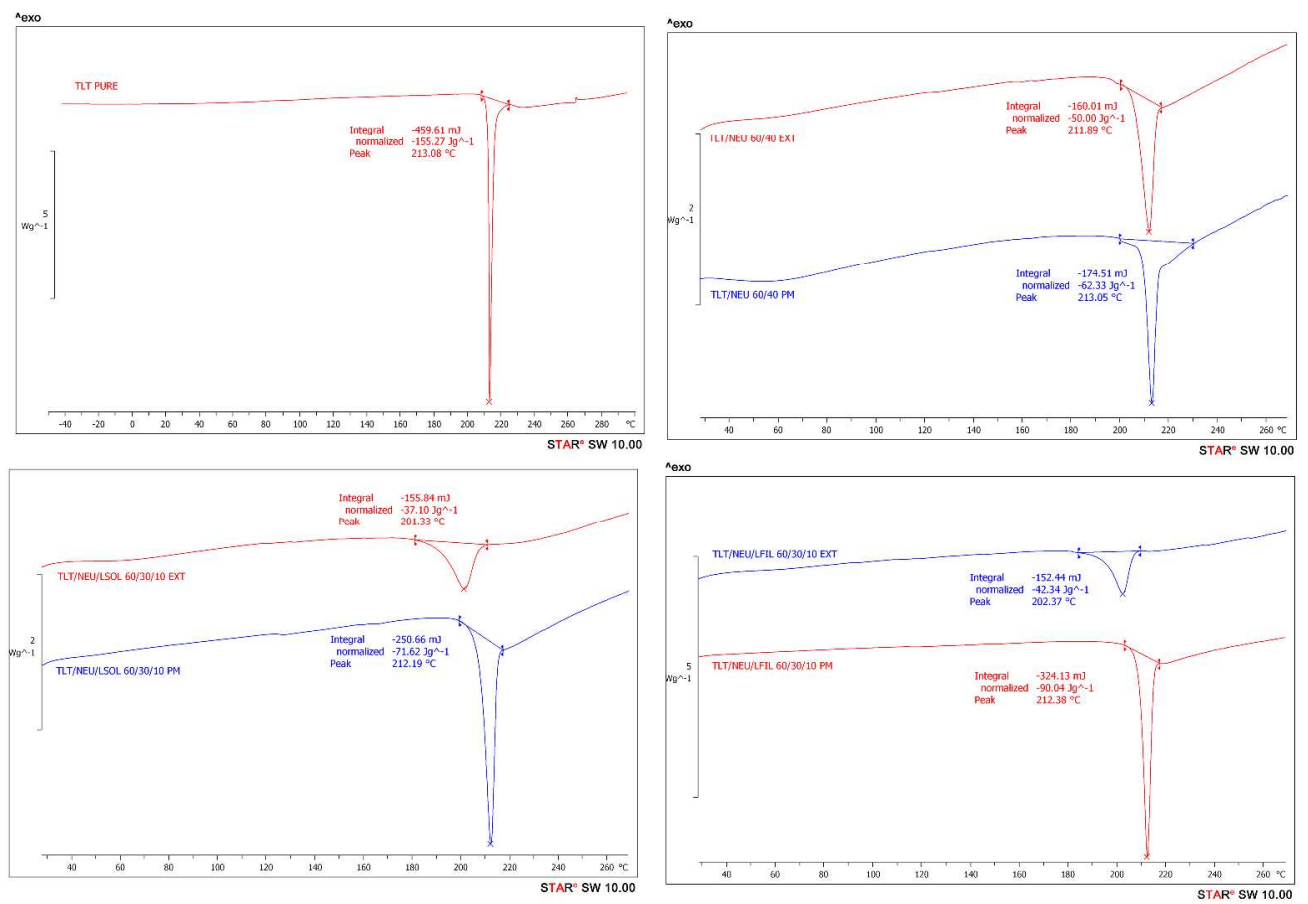

DSC thermal transitions of bulk TLT, TLT/NEU 60/40, TLT/NEU/LSOL 60/30/10 and TLT/NEU/LFIL 60/30/10 formulations.

$1638 \times 1134 \mathrm{~mm}(96 \times 96 \mathrm{DPI})$ 

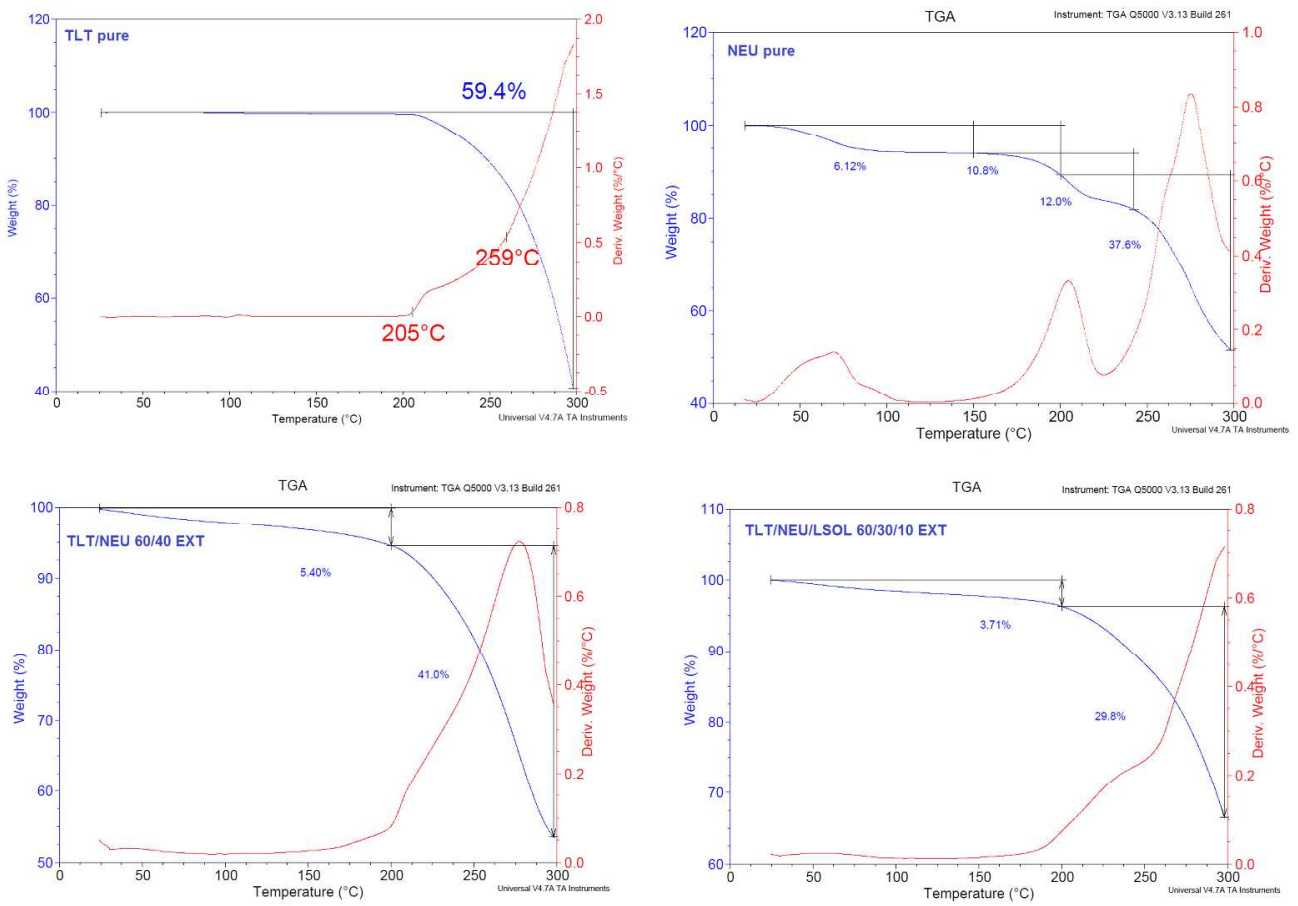

TGA thermograms of bulk TLT, NEU, TLT/NEU and TLT/NEU/LSOL extruded formulations.

$639 \times 445 \mathrm{~mm}(96 \times 96 \mathrm{DPI})$ 

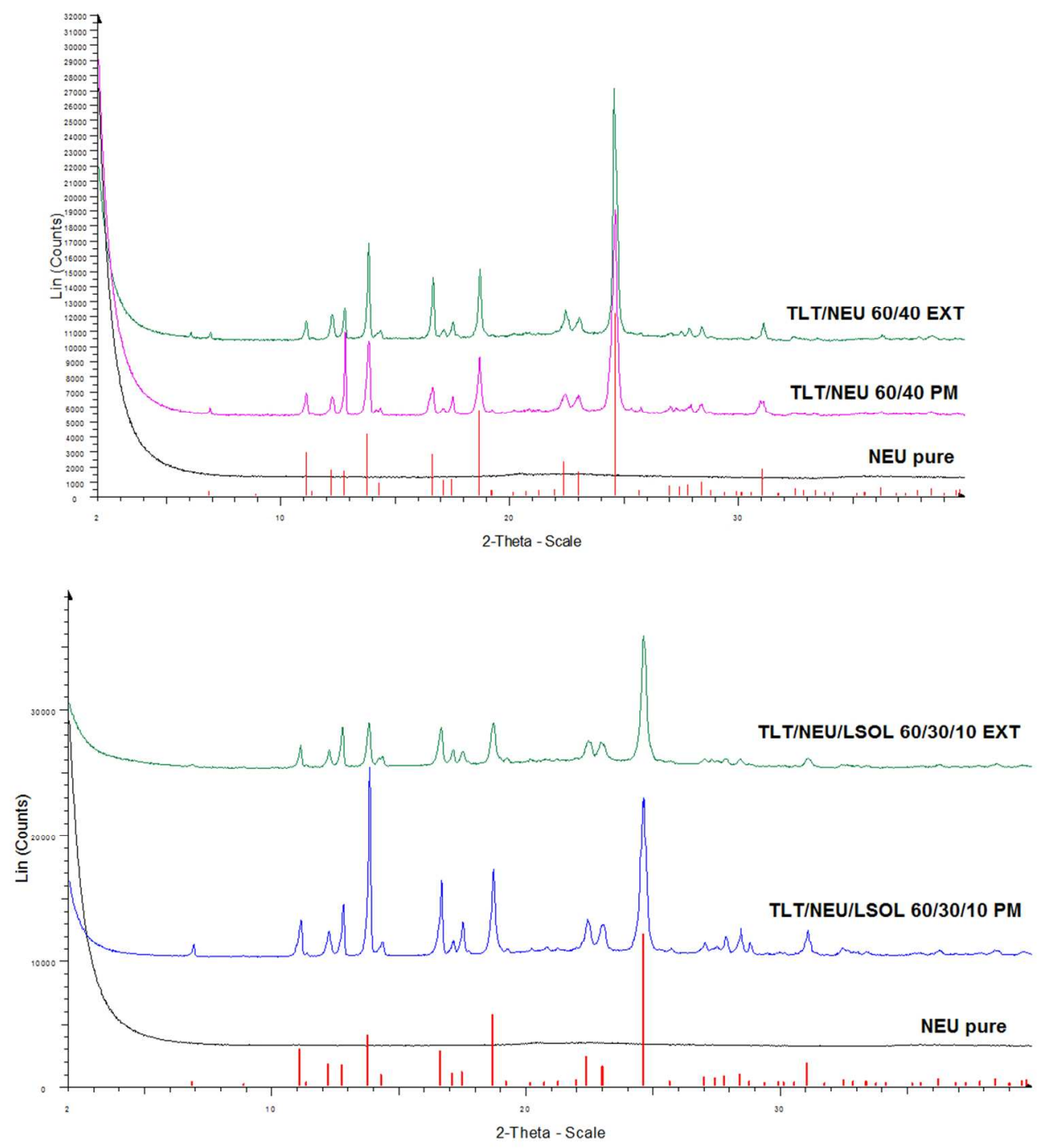

XRD difffractograms of bulk TLT, NEU and TLT based physical mixtures (PM) and extruded formulations (EXT).

$306 \times 334 \mathrm{~mm}(96 \times 96 \mathrm{DPI})$ 


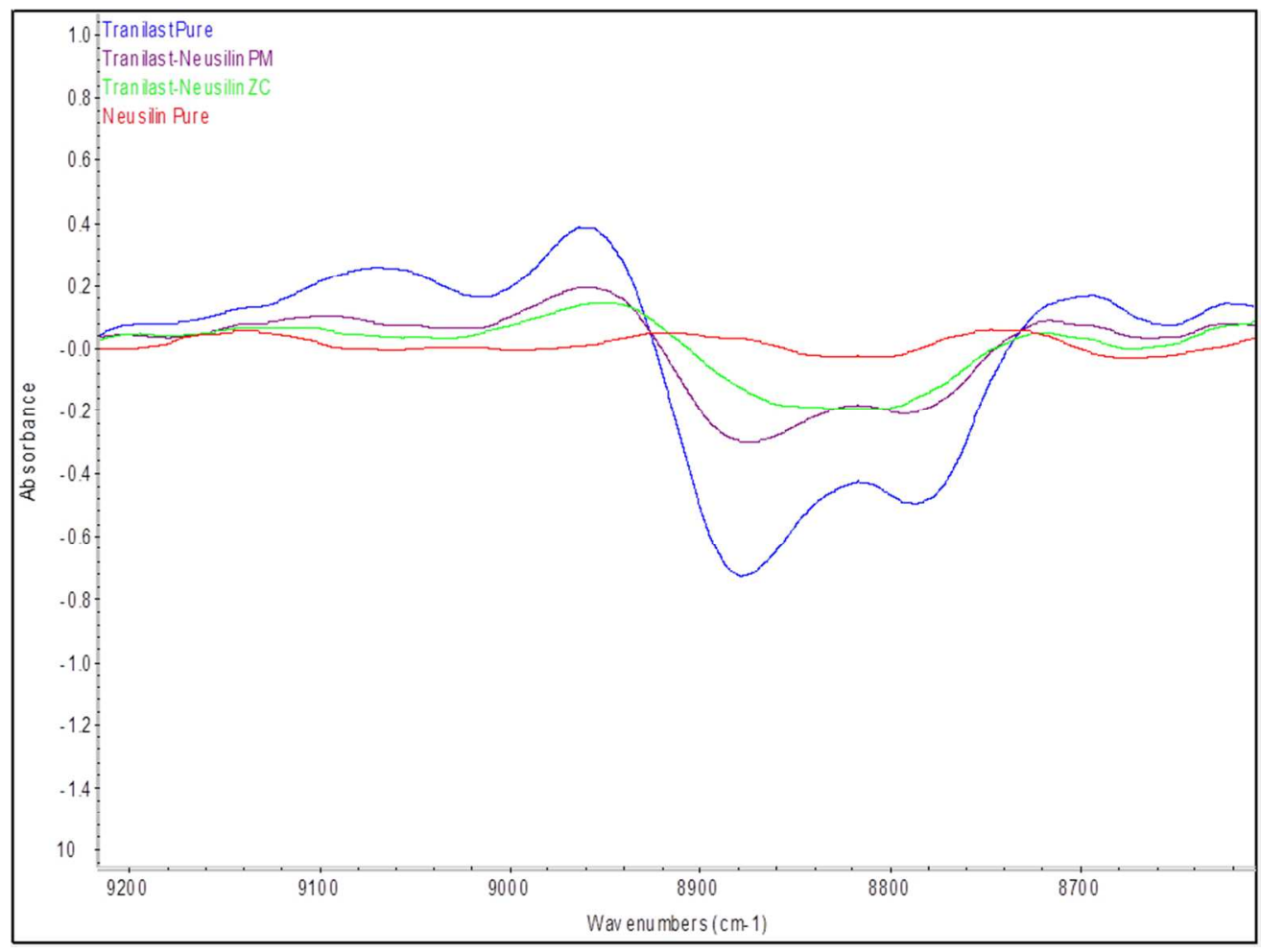

(a-d) 2nd derivative NIR spectra of TLT, NEU and TLT/NEU formulations.

$254 \times 190 \mathrm{~mm}(96 \times 96 \mathrm{DPI})$ 


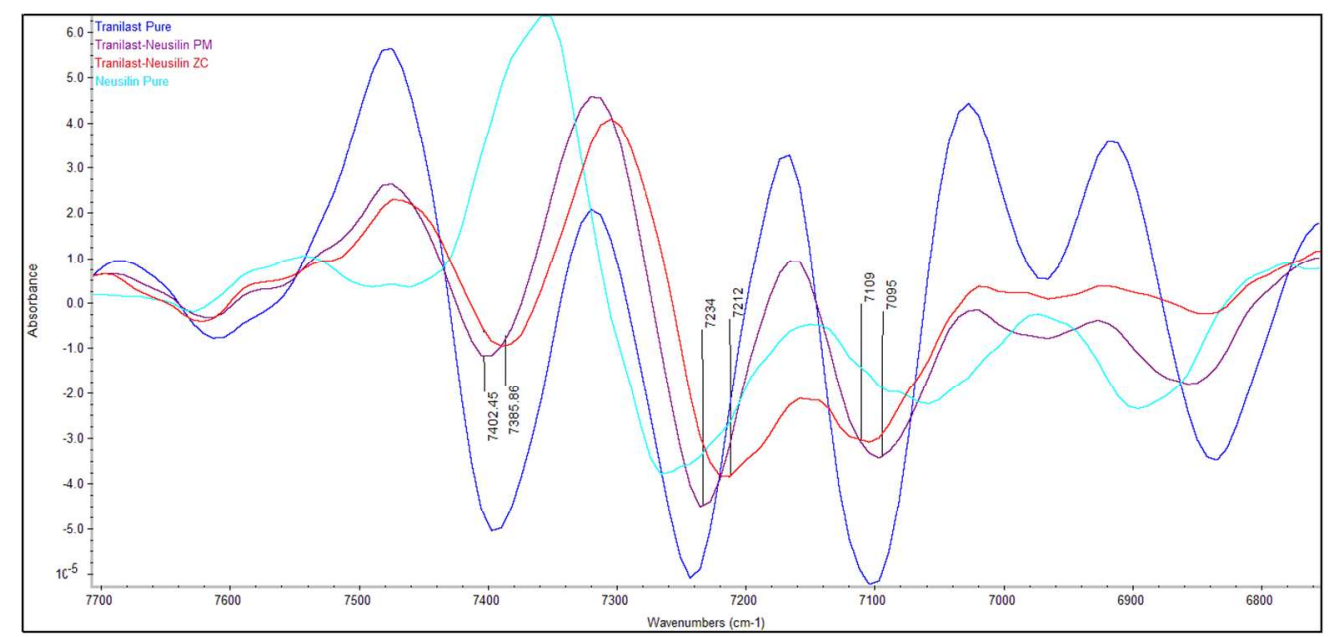

(a-d) 2nd derivative NIR spectra of TLT, NEU and TLT/NEU formulations. $361 \times 172 \mathrm{~mm}(96 \times 96 \mathrm{DPI})$ 


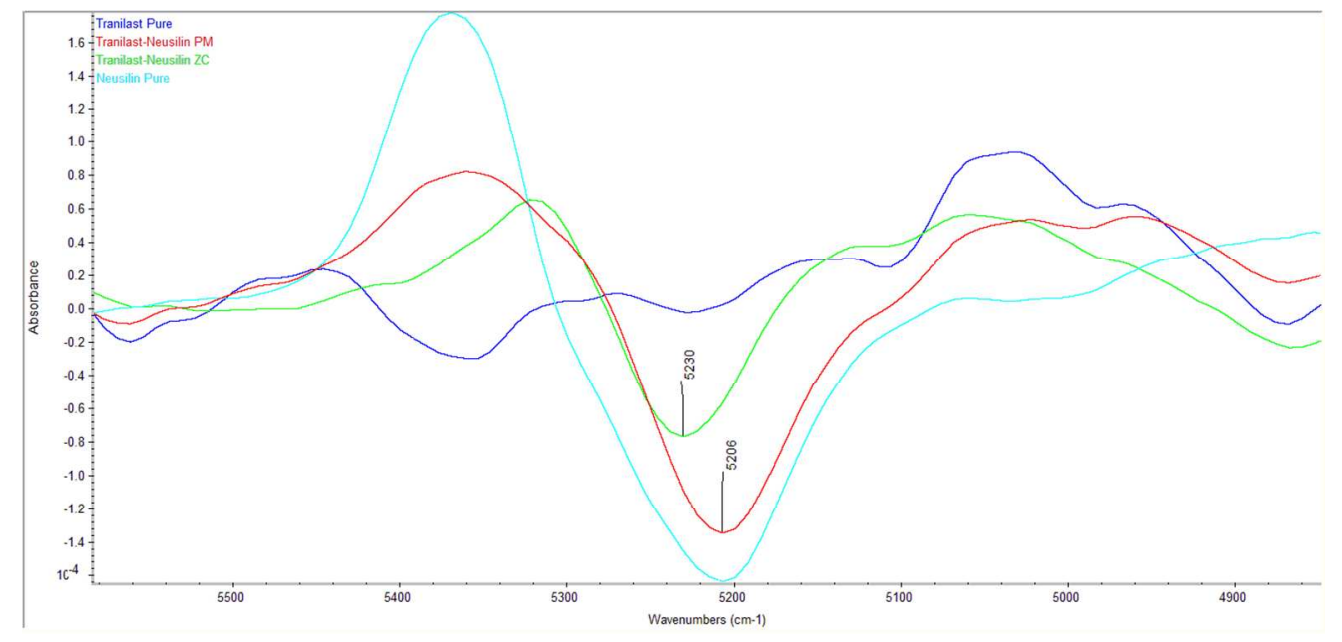

(a-d) 2nd derivative NIR spectra of TLT, NEU and TLT/NEU formulations.

$361 \times 172 \mathrm{~mm}(96 \times 96 \mathrm{DPI})$ 


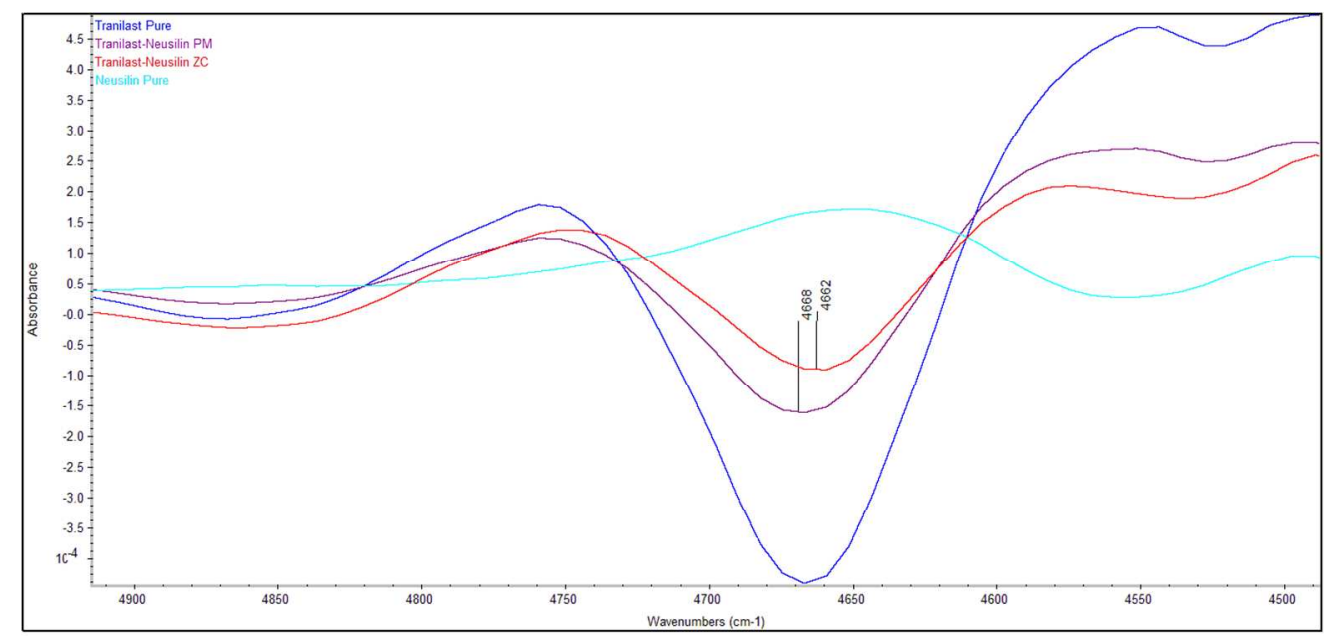

(a-d) 2nd derivative NIR spectra of TLT, NEU and TLT/NEU formulations. $361 \times 172 \mathrm{~mm}(96 \times 96 \mathrm{DPI})$ 


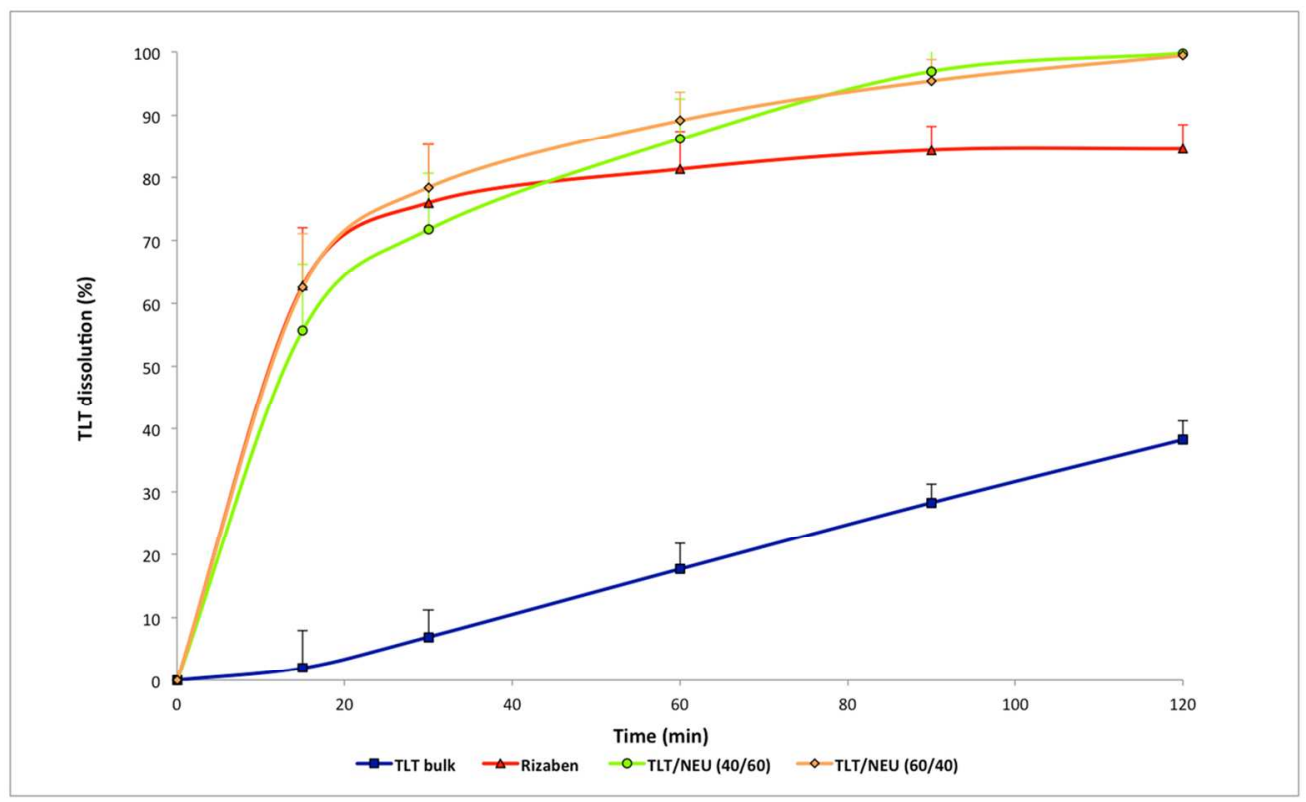

In vitro TLT dissolution profiles of Rizaben and extruded formulation $(n=3, \mathrm{pH} 6.8)$.

$361 \times 221 \mathrm{~mm}(96 \times 96 \mathrm{DPI})$ 


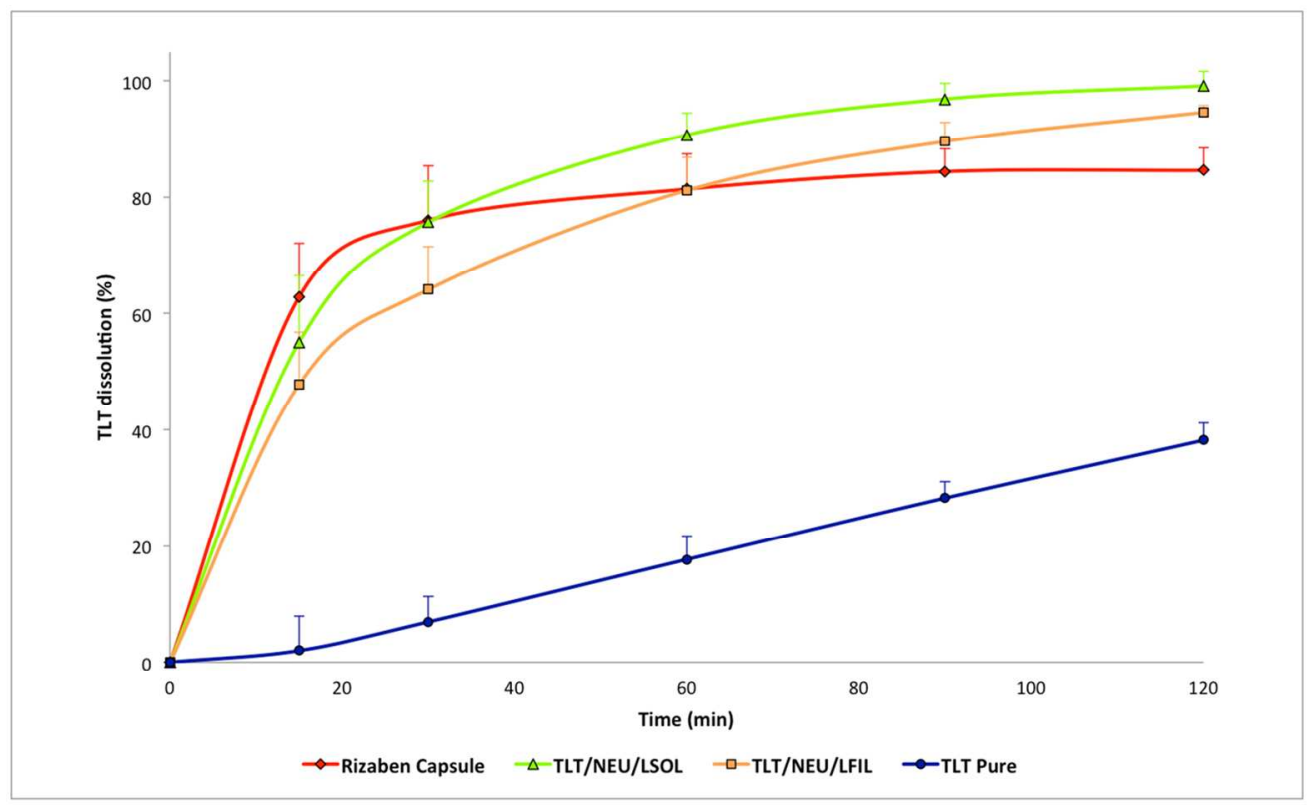

In vitro TLT dissolution profiles of Rizaben and co-processed extruded formulations with NEU/LSOL (LFIL) $(\mathrm{n}=3, \mathrm{pH} 6.8)$.

$360 \times 221 \mathrm{~mm}(96 \times 96 \mathrm{DPI})$ 